\title{
Characterization of coagulase-negative staphylococci from brining baths in Germany
}

\author{
P. Hammer, ${ }^{\star}$ J. Jordan,† C. Jacobs, $\ddagger$ and M. Klempt \\ Department of Safety and Quality of Milk and Fish Products, Max Rubner-Institut, Federal Research Institute of Nutrition and Food, \\ 24103 Kiel, Germany
}

\section{ABSTRACT}

Brining is an important step in cheese making, and using brine baths for this purpose is common practice in German dairies. Time of brining, brine concentration, and composition of the complex and heterogeneous microbiota, including coagulase-negative staphylococci (CNS), contribute to the ripening and taste of cheese. As well as producing staphylococcal enterotoxins, some CNS show antibiotic resistance; therefore, we isolated 52 strains of presumptive CNS from cheese brines from 13 factories in Germany. Species identification by $\operatorname{sod} A$ gene sequencing revealed that 50 isolates were CNS: 31 Staphylococcus saprophyticus, 4 Staphylococcus carnosus, 4 Staphylococcus equorum, 3 Staphylococcus sciuri, 2 Staphylococcus hominis, and 2 Staphylococcus warneri. One isolate each was identified as Staphylococcus epidermidis, Staphylococcus pasteurii, Staphylococcus succinus, and Staphylococcus xylosus. Further subtyping of the Staph. saprophyticus isolates to the subspecies level revealed the presence of 6 Staph. saprophyticus ssp. saprophyticus. Using pulsed-field gel electrophoresis with the identified Staph. saprophyticus strains, 12 independent clones were identified, resulting in the exclusion of 18 strains from further testing. In 19 of the remaining 32 CNS isolates, resistance to antibiotics was observed. Resistance was found against oxacillin (17), penicillin (5), and cefoxitin (1). Four isolates expressed resistance to both oxacillin and penicillin. No resistance was found to enrofloxacin, tetracycline, gentamicin, or erythromycin. Then, PCR analysis for antibiotic resistance genes was performed for 22 different genes. Only genes blaZ and $b l a_{\text {TEM }}$ were found in 7 isolates. These isolates were selected for challenge tests with different concentrations of lactic acid and $\mathrm{NaCl}$ to examine whether expression of antibiotic resistance was influ-

Received August 28, 2018.

Accepted June 19, 2019.

*Corresponding author: philipp.hammer@mri.bund.de

†Current address: Institut Dr. Nowak GmbH \& Co. KG, 28870 Ottersberg, Germany.

$\ddagger$ Current address: State Laboratory of Schleswig-Holstein, 24537 Neumünster, Germany. enced by these stressors. An increase in the minimal inhibitory concentration from 0 to $2.0 \mu \mathrm{g} / \mathrm{mL}$ was seen for trimethoprim/sulfamethoxazole only in one isolate of Staph. saprophyticus at an increased lactic acid concentration. Finally, all isolates were tested for genetic determinants (entA, entB, ent $C$, entD, and entE) of the most common staphylococcal enterotoxins; none of these genes were detected. We found no indication for unacceptable risks originating from the isolated CNS. Key words: antibiotic resistance, coagulase-negative staphylococci (CNS), brining bath, enterotoxin

\section{INTRODUCTION}

Brining baths in cheese factories are used to add salt and other components to freshly pressed and formed cheese for conservation, ripening, and taste. The conditions of the brining process depend on the size, shape, and desired salt content of the cheese being manufactured. The concentration of $\mathrm{NaCl}$ in brine varies from 17 to $22 \%, \mathrm{pH}$ is largely influenced by the $\mathrm{pH}$ of the raw cheese (usually from 5.2 to 5.4), and temperature ranges between 13 and $15^{\circ} \mathrm{C}$. All parameters depend on the process of cheesemaking and the desired type of cheese. The brining process takes from a few hours to several days. The microbiota in the bath includes lactobacilli, lactococci, enterococci, staphylococci, streptococci, several yeasts and fungi; it contributes to the initiation of ripening and has major influence on taste, shelf life, and safety of the produced cheese (Bockelmann and Hoppe-Seyler, 2001; Sutherland, 2002; Montel et al., 2014). Characteristic of brining baths is their very stable microbial composition (Bockelmann and Hoppe-Seyler, 2001), which ensures constant ripening and maintenance of the cheese produced in that bath. Once such a microbiota is established, the baths may be used for years or decades without changes (Neve et al., 2005; > 25 yr of own experience), except for the addition of salt and water to maintain the salt concentration, and for filtration to remove curd particles. Coagulase-negative staphylococci (CNS) are often part of the microbiota because of their high salt tolerance (Bockelmann and Hoppe-Seyler, 2001; Mounier et al., 
2007). The CNS that are present in brining baths are a potential reservoir for microbiotic transfer because identical clones isolated from brine baths have been found in retail cheeses (Mounier et al., 2006).

The CNS are considered to harbor a variety of genes encoding antibiotic resistance, including mecA and mecC (IWG-SCC, 2009; Fontes et al., 2013; ChajęckaWierzchowska et al., 2015). Besides mecA and mecC, other mec genes, such as mecB and mecD, have been identified in Macrococcus caseolyticus (Baba et al., 2009; Schwendener et al., 2017). It has been shown that bacteria are able to distribute genes to other species of the same genus or to other genera (Alonso et al., 2001; Resch et al., 2008). Especially in industrial settings, cheese output can exceed $100,000 \mathrm{~kg} / \mathrm{d}$. If CNS carrying genes that encode antibiotic resistance are present in the brine baths, this might lead to considerable release and distribution of these genes. Sublethal stress may influence the phenotypic expression of antibiotic resistance of bacteria. Stress factors, including $\mathrm{pH}$, salt, or temperature, used in conservation or production of food have been shown to elevate or reduce the expression of antibiotic resistance of Escherichia coli, Salmonella Typhimurium, Staphylococcus aureus, and Listeria monocytogenes (McMahon et al., 2007; Al-Nabulsi et al., 2015).

An additional undesired property of some CNS is the ability to produce staphylococcal enterotoxins. With regard to milk and milk products, genes encoding staphylococcal enterotoxins have been shown for CNS (species not given) from soft cheese (Fontes et al., 2013), for Staph. capitis, Staph. equorum, Staph. lentus, Staph. simulans, and Staph. xylosus from goat milk, whey, and cheese (Vernozy-Rozand et al., 1996b); for Staph. chromogenes, Staph. hyicus, Staph. warneri, and Staph. xylosus isolated from raw cow milk (Oliveira et al., 2010); as well as for Staph. piscifermentans, Staph. saprophyticus, Staph. sciuri, and Staph. xylosus from Minas frescal cheese (fresh cheese, cow milk; Nunes et al., 2016); and for Staph. epidermidis, Staph. hyicus, and Staph. warneri of dairy origin (Rodrigues et al., 2017).

The objective of this study was to characterize CNS isolated from brining baths of different cheese factories in Germany in terms of virulence factors and potential antibiotic resistance, and to test whether antibiotic resistance is influenced by sublethal stress.

\section{MATERIALS AND METHODS}

\section{Brine Bath Samples and Isolation of Staphylococci}

Brine bath samples from 13 German dairies were provided by Horst Neve (Department of Microbiology and
Biotechnology, Max Rubner-Institut, Kiel, Germany). For isolation of staphylococci, $5 \mathrm{~mL}$ of brine fluid was centrifuged at $14,000 \times g$ at $4^{\circ} \mathrm{C}$ for $10 \mathrm{~min}$. The pellet was washed twice with $5 \mathrm{~mL}$ of $0.85 \% \mathrm{NaCl}$ (wt/ vol), applying the same centrifugation conditions. The final pellet was resuspended in $5 \mathrm{~mL}$ of $\mathrm{NaCl}$-peptone $[0.85 \% \mathrm{NaCl}, 0.1 \%$ (wt/vol) tryptone; Oxoid, Wesel, Germany]. Of this suspension, $2 \times 50 \mu \mathrm{L}$ and $2 \times 100$ $\mu \mathrm{L}$ aliquots were surface spread onto Baird-Parker agar (Baird-Parker agar base supplemented with 5\% (vol/ vol) egg yolk tellurite emulsion; both from Oxoid), and incubated for $48 \mathrm{~h}$ at $37^{\circ} \mathrm{C}$. Typical colonies (one of each type) were streaked onto blood agar (Columbia blood agar base supplemented with $5 \%$ (vol/vol) defibrinated sheep blood; both from Oxoid), and incubated for $24 \mathrm{~h}$ at $37^{\circ} \mathrm{C}$. All black or gray colonies with or without a zone of egg yolk precipitation or clearance were regarded as typical on Baird-Parker agar.

\section{Identification of Species}

Isolates from blood agar were identified to the genus level by Gram stain, catalase test, and subculture onto furazolidone agar (von Rheinbaben and Hadlok 1981). As phenotypic tests for species identification, hemolysis, coagulase test with coagulase rabbit plasma with EDTA (Becton Dickinson, Heidelberg, Germany), and API 32 ID STAPH (bioMérieux, Nürtingen, Germany) were applied.

For genotypic identification of species, amplification and partial sequencing of the sodA gene was applied, following the method described by Poyart et al. (2001). For amplification, primers sodAd1 and sodAd2 were used. The PCR products were purified following the GeneJET gel extraction protocol (Thermo Fisher Scientific, Carlsbad, CA). The amplicons were cloned into the pJET1.2/blunt vector following the protocol provided by Thermo Scientific. Sanger sequencing (Sanger and Coulson, 1975) was carried out at LGC Genomics GmbH (Berlin, Germany). As proposed by Poyart et al. (2001), the obtained sequences were trimmed for the 429 -bp fragment within the sodA gene with the dDNAis Max software (Hitachi Software Engineering Co. Ltd., Tokyo, Japan) and analyzed with BLAST (Zhang et al., 2000). The species were determined according to the maximum score.

\section{Pulsed-Field Gel Electrophoresis}

Pulsed-field gel electrophoresis (PFGE) was applied to type isolates of Staph. saprophyticus. For PFGE, the protocol supplied by the Centers for Disease Control PulseNet was used with slight modifications (CDC, 2015). Modifications were as follows: $1.5 \mathrm{~mL}$ of lysis 
buffer was used instead of $3 \mathrm{~mL}$, and $5 \mu \mathrm{L}$ of lysostaphin solution was used instead of $4 \mu \mathrm{L}$. Electrophoresis was performed after restriction with SmaI (Fermentas, St. Leon-Rot, Germany) in a Chef-DR III system (BioRad Laboratories GmbH, Munich, Germany). Running conditions were $16.5 \mathrm{~h}$ at $14^{\circ} \mathrm{C}$, angle $120^{\circ}, 6 \mathrm{~V} / \mathrm{cm}$, and pulse time $5 / 40 \mathrm{~s}$. The gels were digitally photographed in an UV-transilluminator (Gel Doc 2000, Bio-Rad Laboratories $\mathrm{GmbH}$ ). Cluster analysis was performed with GelComparII, version 6.50 (Applied Maths, SintMartens-Latem, Belgium) using the following settings: $1 \%$ optimization, $1.2 \%$ position tolerance. The similarity between band positions was determined by Dice similarity coefficient. For construction of dendrograms, the unweighted pair group method using arithmetic averages (UPGMA) algorithm was selected. For control, Staph. saprophyticus DSM 20229 was used.

\section{Antimicrobial Susceptibility Testing}

For screening of antibiotic susceptibility, the disk diffusion test as described by the Clinical and Laboratory Standards Institute (CLSI, 2008), was applied. For practical reasons, only one substance of each main group of antibiotics was used. Disks and loads were used as follows: cefoxitin $(30 \mu \mathrm{g})$, enrofloxacin $(5 \mu \mathrm{g})$, erythromycin $(15 \mu \mathrm{g})$, gentamicin $(10 \mu \mathrm{g})$, oxacillin (1 $\mu \mathrm{g})$, penicillin $\mathrm{G}(10 \mathrm{U})$, and tetracycline $(30 \mu \mathrm{g})$ (all from Oxoid). For evaluation, breakpoints as proposed by CLSI (2008) and the European Committee on Antimicrobial Susceptibility Testing (EUCAST, 2019) were used.

In addition, MIC were determined utilizing the microdilution method provided by CLSI (2008). The MIC for all strains were determined for oxacillin and the respective antibiotics for all strains showing genetic determinants of antibiotic resistance. Again, the breakpoints as provided by CLSI (2008) and EUCAST (2019) were applied for evaluation.

\section{Genetic Determinants for Antibiotic Resistance, and Production of Enterotoxin and Coagulase}

Reference strains, primers, and PCR conditions for all PCR reactions applied for detection of genetic determinants of antibiotic resistance, enterotoxin production, and coagulase are listed in Tables 1 and 2 .

The DNA extraction from samples was performed as follows: Isolates were incubated on blood agar at $36^{\circ} \mathrm{C}$ for $24 \mathrm{~h}$. Single colonies were picked and incubated in $5 \mathrm{~mL}$ of the medium showing the best growth [brain heart infusion broth (BHI), Todd-Hewitt broth

Table 1. Bacterial strains used as controls in PCR for detection of enterotoxin, antibiotic resistance, and coagulase genes

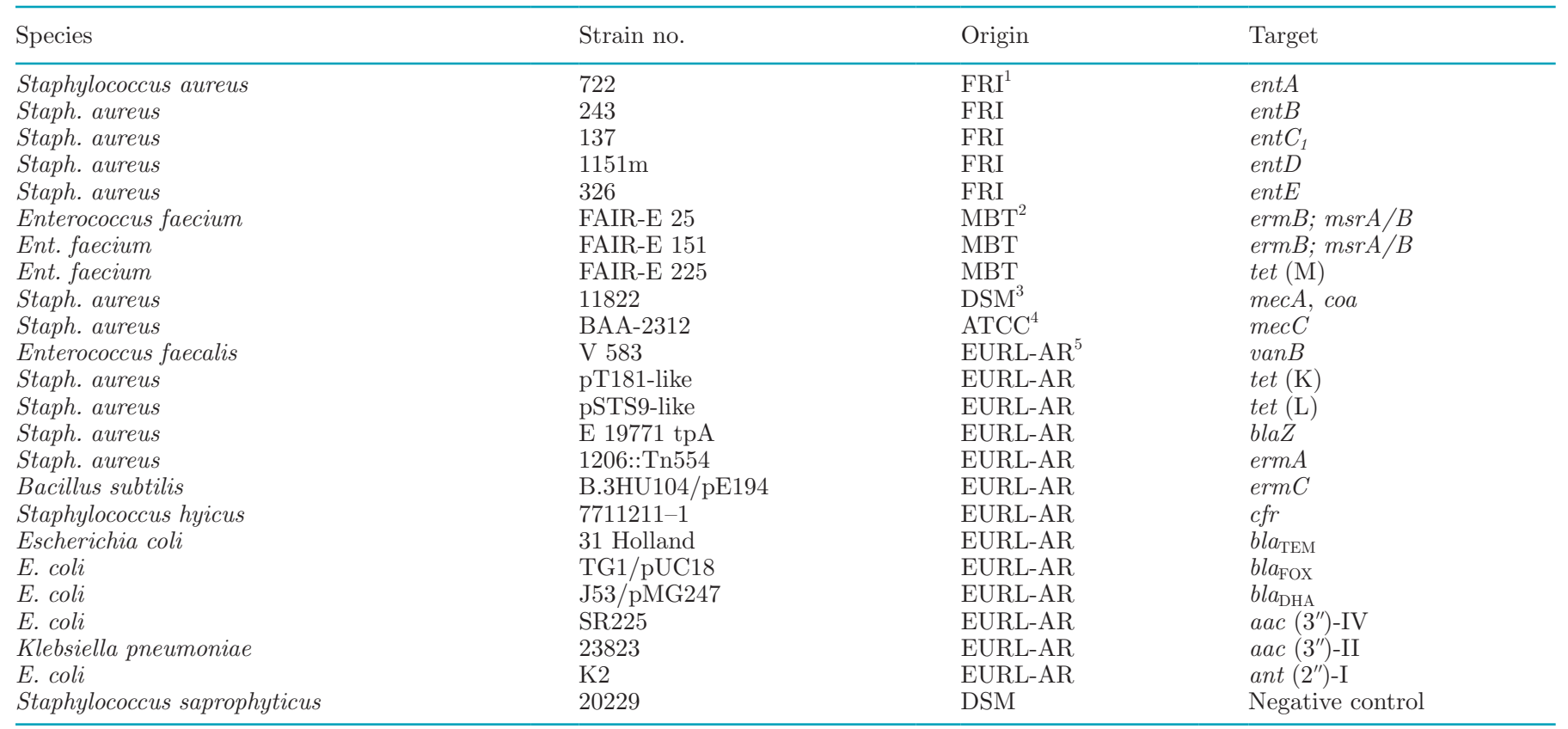

${ }^{1}$ Food Research Institute (Madison, WI).

${ }^{2}$ Department of Microbiology and Biotechnology, Max Rubner-Institute (Kiel, Germany; Hummel et al., 2007).

${ }^{3}$ German Collection of Microorganisms and Cell Cultures (Leibniz Institute, Braunschweig, Germany).

${ }^{4}$ American Type Culture Collection (Manassas, VA).

${ }^{5}$ European Union Reference Laboratory-Antimicrobial Resistance (Lyngby, Denmark). 
Table 2. List of primers and annealing temperatures used for the PCR in this study

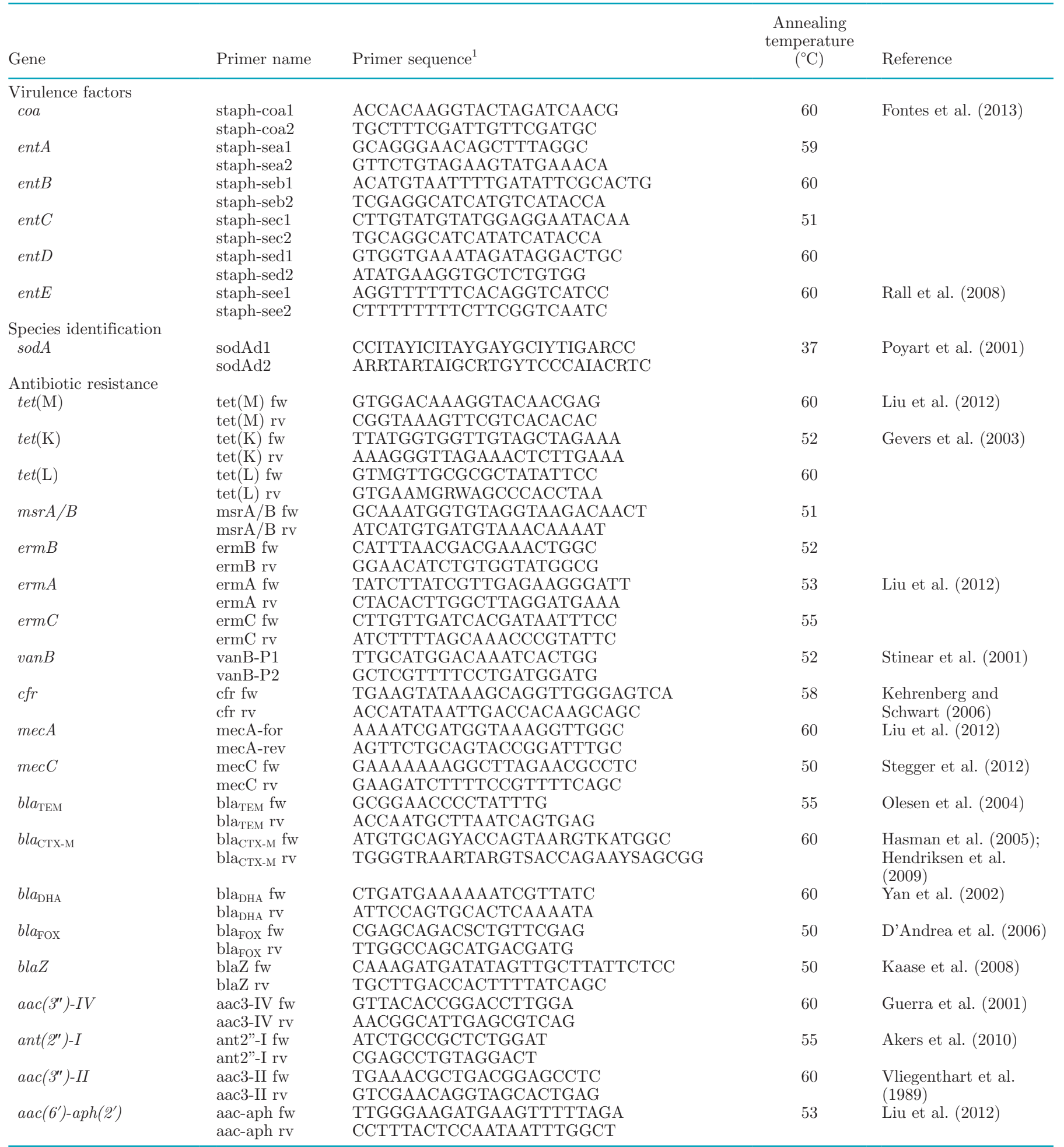

${ }^{1} \mathrm{R}=\mathrm{A}$ and $\mathrm{G} ; \mathrm{W}=\mathrm{A}$ and $\mathrm{T} ; \mathrm{Y}=\mathrm{C}$ and $\mathrm{T} ; \mathrm{S}=\mathrm{G}$ and $\mathrm{C} ; \mathrm{M}=\mathrm{A}$ and $\mathrm{C} ; \mathrm{K}=\mathrm{G}$ and $\mathrm{T} ; \mathrm{I}=\mathrm{A}, \mathrm{C}, \mathrm{G}$, and $\mathrm{T}$

(THB), or tryptone soy broth (TSB); all from Oxoid], at $36^{\circ} \mathrm{C}$ for $24 \mathrm{~h}$ on a shaker $(100 \mathrm{rpm})$. From each culture, 2 to $4 \mathrm{~mL}$ was centrifuged at $5,000 \times g$ for 10 min. The supernatant was discarded and the cells were stored at $-20^{\circ} \mathrm{C}$. Cell-wall lysis was accomplished by adding $20 \mu \mathrm{L}$ of lysostaphin $(5 \mathrm{mg} / \mathrm{mL}$; Sigma-Aldrich 
Chemie GmbH, Munich, Germany) and $180 \mu \mathrm{L}$ of 20 $\mathrm{m} M$ Tris- $\mathrm{HCl}$ (pH 8.0), $2 \mathrm{~m} M$ EDTA, and $1.2 \%$ Triton (TET; AppliChem GmbH, Darmstadt, Germany) to the pellet. The mixture was incubated overnight at $37^{\circ} \mathrm{C}$. The DNA was purified using the QIAamp DNA Mini Kit (Qiagen GmbH, Hilden, Germany). Departing from the protocol provided with the kit, $20 \mu \mathrm{L}$ of proteinase $\mathrm{K}$ and $200 \mu \mathrm{L}$ of buffer $\mathrm{AL}$ (both from the kit) were added to the mixture and incubated at $56^{\circ} \mathrm{C}$ for $30 \mathrm{~min}$. Another incubation step at $95^{\circ} \mathrm{C}$ for $15 \mathrm{~min}$ was added. The next steps were carried out according to the protocol (QIAamp DNA Mini and Blood Mini Handbook 02/2015, p. 34-35, step 6-11; https: //www.qiagen.com/ch/resources/download.aspx?id= 62a200d6-faf4-469b-b50f-2b59cf738962\&lang=en). The concentration of DNA was measured with a NanoPhotometer (Implen GmbH, Munich, Germany). For the reference strains obtained from EURL-AR (Table 1), boiling lysates were used as positive controls for PCR as recommended. These were produced by picking 1 to 3 colonies grown on blood agar and dissolving them in TET solution. Afterward, the tubes were boiled for $10 \mathrm{~min}$, centrifuged for $5 \mathrm{~min}$ at $20,000 \times g$, diluted 1:10 in TET solution, and stored at $-20^{\circ} \mathrm{C}$. The DNA of all other reference strains (Table 1) was purified as mentioned before.

Sample and reference DNA were diluted to 1 to 20 $\mathrm{ng} / \mu \mathrm{L}$ before the PCR reactions were performed. The PCR were performed on a Labcycler (Sensoquest, Göttingen, Germany) in a final volume of $20 \mu \mathrm{L}$ containing $1 \mu \mathrm{L}$ of DNA as the template, $0.3 \mu M$ each primer (Table 2, TIB MolBiol GmbH, Berlin, Germany), $0.4 \mu M$ dNTPs, 1 U of HOT FIREPol DNA Polymerase (Solis BioDyne, Tartu, Estonia), $1 \times$ reaction buffer B $[0.8 M$ Tris-HCl, $0.2 M\left(\mathrm{NH}_{4}\right)_{2} \mathrm{SO}_{4}, 0.2 \%$ wt/vol Tween-20],

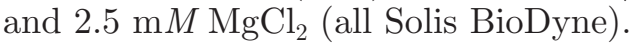

\section{Challenge Tests}

To test whether sublethal acidic and osmotic stress would change antibiotic susceptibility, 7 isolates that showed antibiotic resistance were chosen, and the tests were performed according to McMahon et al. (2007). Briefly, approximately $10^{6} \mathrm{cfu}$ of each isolate was inoculated in $10 \mathrm{~mL}$ of brain heart infusion broth (BHI) adjusted with lactic acid to different $\mathrm{pH}$ values (5.0, $7.0,6.5,5.5,5.0,4.5,4.0,3.5,3.0)$ or adjusted with $\mathrm{NaCl}$ to different salt concentrations $(0,3,4,4.5,5$, $5.5,6,10,12,13,13,15,18 \%)$. For each strain, the sublethal stress level was defined as the $\mathrm{pH}$ or $\mathrm{NaCl}$ concentration that reduced growth at least by $75 \%$ as measured by optical density at $600 \mathrm{~nm}\left(\mathrm{OD}_{600}\right)$ after overnight incubation at $37^{\circ} \mathrm{C}$.
For MIC testing at sublethal stress, BHI prepared as described above was used to inoculate commercially prepared microtiter plates containing 25 different antibiotics (Micronaut-S MVZ Saar GP2, Merlin Diagnostica, Bornheim, Germany). Antibiotics and loads per well are listed in Table 3. Testing was performed 3 times for each isolate.

\section{RESULTS AND DISCUSSION}

Brine samples from 13 cheesemaking facilities were examined for the presence of CNS. In total, 52 isolates were obtained and further characterized utilizing phenotypic and genotypic tests. A group of selected strains showing antibiotic resistance were used for challenge tests.

\section{Identification of Species}

All strains were gram-positive cocci with a positive catalase reaction. As expected for staphylococci, they did not grow on furazolidone agar containing $20 \mu \mathrm{g} /$ $\mathrm{mL}$ of the antibiotic, whereas micrococci would (von Rheinbaben and Hadlok 1981).

Partial sequencing of the sodA gene resulted in BLAST identifications between 99 and 100\%. Two strains were identified as Macrococcus caseolyticus. Ten Staphylococcus species were identified (no. of isolates): Staph. saprophyticus (31), Staph. carnosus (4), Staph. equorum (4), Staph. sciuri (3), Staph. hominis (2), Staph. warneri (2), Staph. epidermidis (1), Staph. pasteurii (1), Staph. succinus (1), and Staph. xylosus (1). This is in good agreement with findings of Coton et al. (2010), who mostly detected Staph. equorum, Staph. xylosus, Staph. epidermidis, and Staph. saprophyticus on cheese; and with Organji et al. (2018), who found Staph. equorum, Staph. epidermidis, and Staph. caprae on cheese. Mounier et al. (2006) detected several CNS (Staph. epidermidis, Staph. equorum, Staph. pasteurii, Staph. saprophyticus) in the environment, in brine baths, and on cheese in a dairy that produced smear-ripened cheese. Furthermore, they found identical clones of Staph. saprophyticus in brine baths and on the respective cheeses.

Phenotypic testing using API 32ID STAPH showed congruent results to $\operatorname{sod} A$ sequencing in 20 cases. For 2 strains, no API profile could be obtained. Compared with $\operatorname{sod} A$ sequencing, 3 isolates were identified as Staph. xylosus instead of Staph. equorum. Four strains identified by sequencing as Staph. carnosus showed profiles of Staph. saprophyticus (2), Staph. kloosii (1), and Staph. xylosus (1). Further mismatches ( $\operatorname{sodA}$ vs. API) were Staph. succinus versus Staph. xylosus, Staph. 
Table 3. Antibiotics and respective loads per well onto commercially prepared microtiter plates for MIC testing

\begin{tabular}{lll}
\hline Substance & Abbreviation & Loads per well $(\mu \mathrm{g} / \mathrm{mL})$ \\
\hline Ampicillin & AMP & 8,2 \\
Ampicillin/sulbactame & AMS & $8 / 4$ \\
Cefacolin & CEZ & 8 \\
Cefoxitin & COX & 4 \\
Ceftriaxone & CRO & $2,1,0.5$ \\
Imipenem & IMP & $4,0.5,0.125$ \\
Meropenem & MER & $4,0.5,0.25$ \\
Oxacillin & OXA & $2,0.25$ \\
Penicillin & PEN & $2,0.125,0.0625$ \\
Piperacillin & PIP & 8 \\
Piperacillin/tazobactam & PIT & $8 / 4$ \\
Tetracycline & TET & 4,2 \\
Tigecyclin & TGC & 0.5 \\
Linezolid & LIZ & 4,2 \\
Erythromycin & ERY & $0.5,0.25$ \\
Daptomycin & DPT & 4,1 \\
Clindamycin & CLI & $0.5,0.25$ \\
Vancomycin & VAN & $4,2,1$ \\
Trimethoprim/sulfamethoxazole & T/S & $2 / 38,0.5 / 9.5$ \\
Ciprofloxacin & CIP & 2,1 \\
Levofloxacin & LEV & 2,1 \\
Rifampicin & RAM & 1 \\
Gentamicin & GEN & 8,4 \\
Tobramycin & TOB & 4 \\
Fosfomycin & FOS & 32 \\
\hline
\end{tabular}

pasteurii versus Staph. warneri, and Staph. hominis versus Staph. haemolyticus (Table 4). Similar observations regarding differing results of species identification of the 2 methods were reported by Poyart et al. (2001), supporting a greater discriminative power of $\operatorname{sod} A$ sequencing compared with phenotypic testing.

After excluding 18 isolates of Staph. saprophyticus after testing with PFGE (see below), 32 isolates were tested further: 25 did not show hemolysis on blood agar, 3 exhibited $\alpha$-hemolysis, and $4 \beta$-hemolysis. All were coagulase negative according to phenotypic and genotypic tests.

As multiple strains of Staph. saprophyticus were isolated from different brine baths, 30 isolates were typed by PFGE to examine clonal relatedness. Twelve pulsotypes were identified, which resulted in the exclusion of 18 strains from further testing (data not shown). Staphylococcus saprophyticus ssp. saprophyticus is a biosafety level 2 organism and should not be present in brine baths, whereas subspecies bovis is classified as a level 1 organism. According to Hájek et al. (1996) and the respective UK standard (Anonymous, 2014), the subtypes can be differentiated by phenotypic tests for nitrate reductase, pyrrolidonyl arylamidase, and D-ribose fermentation; Staph. saprophyticus ssp. saprophyticus is negative for all of these tests. Negative reactions in all tests were obtained with 6 of the isolates, indicating that these belong to the subspecies saprophyticus, whereas the remaining isolates showed positive reactions with some of the tests and were left untyped (subspecies bovis should show positive results in all tests). As sodA sequencing did not help to identify the subtypes and rpoB sequencing is likewise not a useful additional test (Mellmann et al., 2006), an attempt to further subtype the questionable strains will be done by whole-genome sequencing.

A frequent occurrence of Staph. saprophyticus in cheese was reported by Nunes et al. (2016; 4 isolates from 10 samples of Minas frescal cheese), by Kürekci (2016; 6 isolates from 17 different cheese types in Turkey), and others (Vernozy-Rozand et al., 1996a; Irlinger et al., 1997; Delbès and Montel, 2005; Mounier et al., 2006). Typing to the subspecies level was not performed by any of the working groups cited above. The occurrence of Staph. saprophyticus ssp. saprophyticus in brine, as we have shown here, does not necessarily imply that these bacteria are transferred to cheese, although that is most likely (for review, see Irlinger et al., 2015). In fact, such a transfer has already been demonstrated (Mounier et al., 2006). Further experiments will reveal whether the clones we isolated from brine can be found on respective retail cheeses. As Staph. saprophyticus (without differentiation to the subspecies level) is the second most frequent causative organism of uncomplicated urinary tract infection (UTI) in women and can cause UTI in males of all ages (Raz et al., 2005), the occurrence of this organism in brine raises concerns regarding the safety of cheese. However, although 


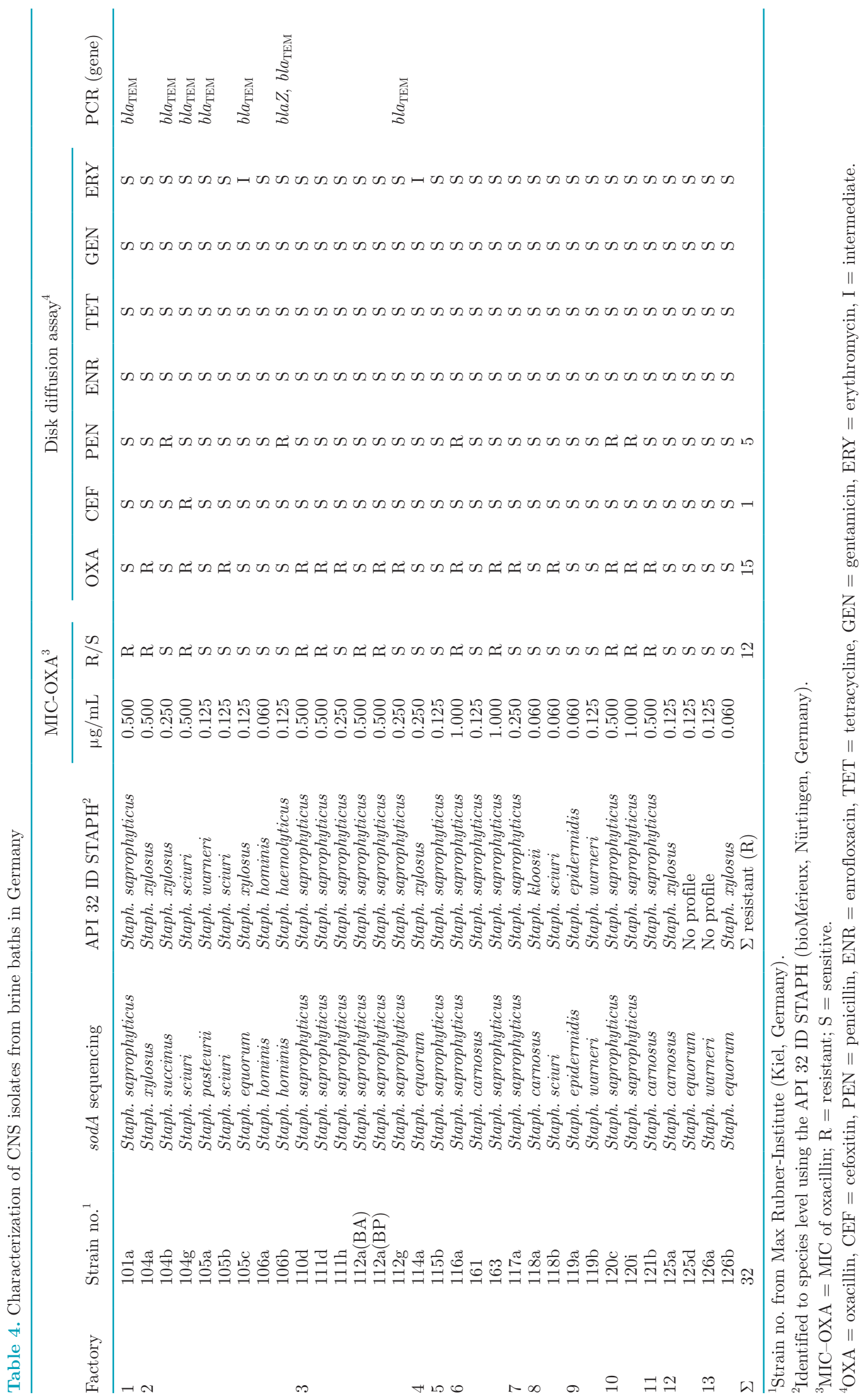


Staph. saprophyticus is a common bacterium found on skin of humans and animals and on other food besides from cheese (Hovelius and Mardh, 1984; Hedman et al., 1990), to date there is no proven case (by clonal identification) of food-borne UTI reported. Coagulasenegative staphylococci as starter cultures, in general, must not harbor virulence factors (Irlinger 2008). It would be interesting to evaluate the pathogenic potential of the Staph. saprophyticus ssp. saprophyticus clones and other species (Staph. carnosus, Staph. sciuri, Staph. warneri) isolated from brine in this study.

\section{Antimicrobial Susceptibility Testing}

All isolates were tested for antimicrobial susceptibility by applying phenotypic and genetic tests (Table 4). For screening purposes, we used the disk diffusion test for representatives of the 5 main groups of antibiotics (penicillin, enrofloxacin, tetracycline, gentamicin, and erythromycin). Five of 32 strains showed resistance to penicillin and 2 strains showed intermediate resistance to erythromycin. In addition, to screen for methicillin resistance, disk diffusion assays with cefoxitin and oxacillin and MIC tests for oxacillin were utilized. Only one strain displayed resistance to cefoxitin, whereas, for oxacillin, 15 isolates showed resistance in the disk diffusion test and 12 with the MIC test. The MIC values for resistant strains were close to the respective breakpoints, which indicates low-level resistance (Table 4). The same was true for the zone diameters of disk diffusion tests (data not shown). In 6 cases, results for the disk diffusion and MIC tests for oxacillin were not consistent. Five isolates showed resistance by disk diffusion assay and a negative MIC test, and one showed the opposite. Differences in test results are well known for both tests (for review, see Jorgensen and Ferraro, 2009). None of the strains resistant to oxacillin by MIC or disk diffusion assay or resistant to cefoxitin showed a positive PCR result for mecA or mecC genes. This confirms a study showing that methicillin-resistant $M$. caseolyticus isolated from bulk tank milk contained neither mecA nor mecC (MacFadyen et al., 2018). In this case, methicillin resistance was encoded mostly by the mecD gene, which was originally isolated from mastitic milk (Schwendener et al., 2017). A further source of methicillin resistance is the $m e c B$ gene, which has been naturally transferred from $M$. caseolyticus to Staph. aureus (Becker et al., 2018). Further investigations will reveal which gene encodes for the methicillin resistance observed in the present study.

To evaluate the phenotypic tests, we applied breakpoint tables provided by CLSI (2008) and EUCAST (2019). Regarding MIC of oxacillin, both tables rec- ommended the same breakpoint $(0.5 \mu \mathrm{g} / \mathrm{mL})$. For disk diffusion, the test zone diameters for breakpoint estimation provided by EUCAST for most of the antibiotics were larger than those provided by CLSI. In these cases, we used the CLSI breakpoints. For cefoxitin, the same breakpoints were given by both organizations, and for oxacillin and enrofloxacin, no breakpoints were provided by EUCAST.

In total, 20 PCR tests were applied to testing for genes encoding antibiotic insensibility. The bla $a_{\text {TEM }}$ gene was detected in 6 strains and $b l a_{\mathrm{TEM}}$ and blaZ in one strain. For these strains, the MIC for penicillin were determined. All were sensitive to this antibiotic, although one strain of Staph. succinus and one strain of Staph. hominis were resistant to penicillin in the disk diffusion assay. This is similar to the results obtained for oxacillin.

Interestingly, most strains displaying phenotypic or genetic resistance were from factory 2 , which unlike all other factories produced cheese exclusively from raw milk (Table 4). This may also explain the diversity of species present in the brine bath of this dairy.

In contrast to reports from other authors on CNS from different cheese types in Turkey (Kürekci, 2016), Minas frescal cheese, or from cheese processing environments from Brazil (Nunes et al., 2016; Rodrigues et al., 2017) only 4 strains showed resistance to both oxacillin and penicillin. No further multiresistant strains were detected in this study.

\section{Challenge Tests}

Based on the experimental setup of McMahon et al. (2007), 7 selected isolates were challenged in a first step with sublethal concentrations of lactic acid and salt. In these isolates, genes encoding $\beta$-lactamase (blaTEM or blaZ) were found and phenotypic resistance against $\beta$-lactam antibiotics (OXA and PEN) were detected (strains 101a, 104b, 104g, 105a, 105c, 106c, 112g; Table 4). Utilizing BHI with different concentrations of lactic acid or $\mathrm{NaCl}$, we determined the optimum growth conditions and reduction of growth by $25 \%$, measured as reduction in $\mathrm{OD}_{600}$, and by $75 \%$ (sublethal stress level according to McMahon et al., 2007) (Table 5). Twentyfive antibiotics or combinations of antibiotics were used to challenge the selected strains with sublethal stress. Only 3 strains showed altered antibiotic resistance, all during challenge with acid (Table 6). Staphylococcus hominis (106b) showed slightly decreased resistance to penicillin, as did one strain of Staph. saprophyticus (101a). Another Staph. saprophyticus (112g) isolate displayed increased resistance to trimethoprim/sulfamethoxazole at a low level. For erythromycin and 


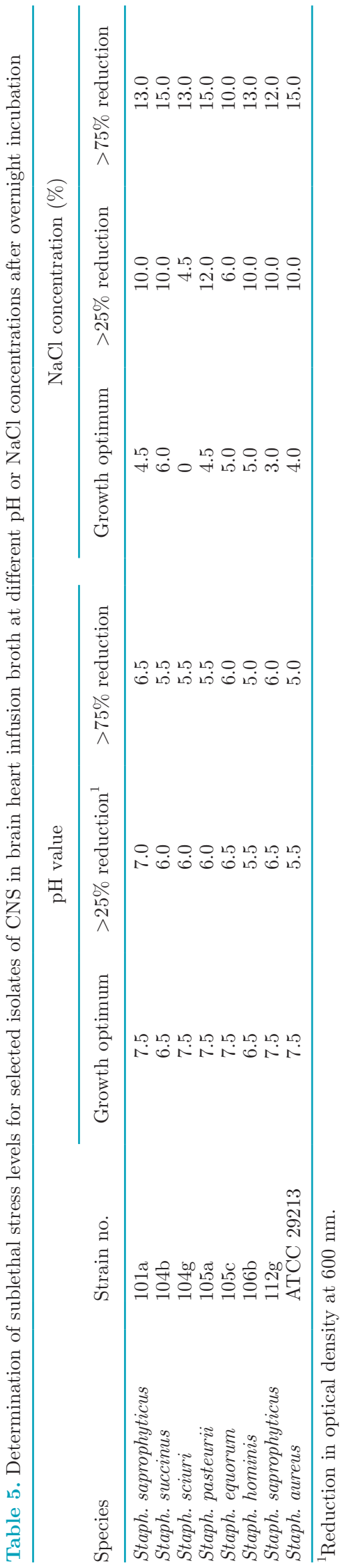

oxacillin (both used in the challenge tests), McMahon et al. (2007) reported strong effects during challenge of 4 isolates of Staph. aureus with $\mathrm{NaCl}$ and acid. The MIC for erythromycin increased up to 3 times under challenge with $\mathrm{NaCl}$ and acid. For oxacillin, the MIC decreased up to 3 -fold under the challenged conditions except for a 3 -fold increase for one isolate during challenge with $\mathrm{NaCl}$. The obvious higher stability of the selected isolates in this study against a challenge with salt and acid may be due to their adaptation to brine baths for many years or even decades.

\section{Genetic Determinants for Enterotoxin Production}

All isolates were tested for genetic determinants of the most common staphylococcal enterotoxins entA, ent $B$, ent $C$, entD, and entE. None of these genes were detected. Similar results were obtained by Rodrigues et al. (2017) with CNS from dairies. None of the abovementioned enterotoxin genes were found in Staph. epidermidis, Staph. hyicus, or Staph. warneri; however, some rarer staphylococcal enterotoxin genes were present in those isolates. In contrast, gene and enterotoxin expression for all abovementioned common staphylococcal enterotoxins (and several others) was demonstrated for Staph. piscifermentans, Staph. saprophyticus, Staph. sciuri, and Staph. xylosus (Nunes et al., 2016). Expression and genetic determinants for SEE were detected in Staph. capitis, Staph. equorum, Staph. lentus, Staph. simulans, and Staph. xylosus (Vernozy-Rozand et al., 1996b). Production of SEC and SED by Staph. chromogenes in skim milk was reported by Oliveira et al. (2010). With regard to these findings, further testing of the brine bath isolates may be worthwhile.

\section{CONCLUSIONS}

The microbiota (including CNS) of brine baths contributes to cheesemaking in an essential way and should not be of concern for food safety. For the group of CNS investigated in this study, we showed that genes encoding common enterotoxins were not present. Few genes encoding for antibiotic resistance were detected in a small number of isolates, whereas a considerable number expressed antibiotic resistance at a low level. Some of the isolated species could be of concern in terms of biosafety, especially the relatively high numbers of Staph. saprophyticus ssp. saprophyticus detected. Based on these results, no indication of unacceptable risk originating from the isolated CNS was found. For a final assessment of the isolates in terms of food safety, further investigations, especially whole-genome sequencing, should be applied. 
Table 6. Influence of sublethal stress on antibiotic resistance of CNS from brine baths

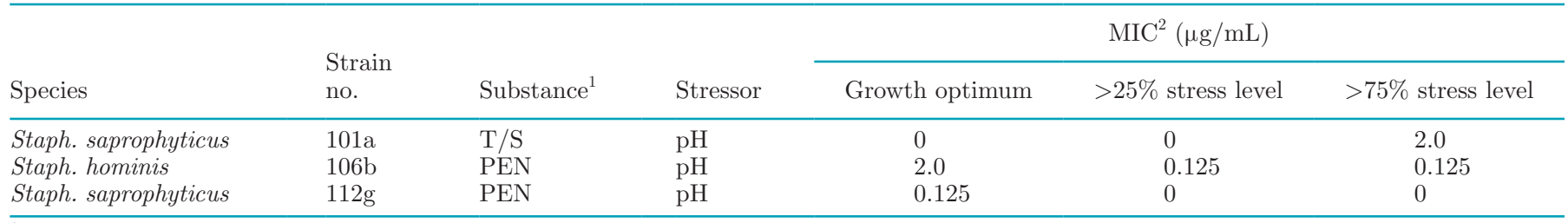

${ }^{1} \mathrm{~T} / \mathrm{S}=$ trimethoprim/sulfamethoxazole; $\mathrm{PEN}=$ penicillin.

${ }^{2}$ Median of 3 repeats.

\section{ACKNOWLEDGMENTS}

The authors thank Beate Bonniksen, Tjark Dopp, Svenja Feuerhahn, Silvia Kaschner, Kevin Pohl, Maren Schmidt, and Raik Timm (Max Rubner-Institute, Department of Safety and Quality of Milk and Fish Products, Kiel, Germany) for their excellent technical assistance.

\section{REFERENCES}

Akers, K. S., C. Chaney, A. Barsoumian, M. Beckius, W. Zera, X. Yu, C. Guymond, E. F. Keen III, B. J. Robinson, K. Mende, and C. K. Murray. 2010. Aminoglycoside resistance and susceptibility testing errors in Acinetobacter baumannii-calcoaceticus complex. J. Clin. Microbiol. 48:1132-1138.

Al-Nabulsi, A. A., T. M. Osaili, A. A. Shaker, A. N. Olaimat, Z. W. Jaradat, N. A. Zain-Elabedeen, and R. A. Holley. 2015. Effects of osmotic pressure, acid, or cold stresses on antibiotic susceptibility of Listeria monocytogenes. Food Microbiol. 46:154-160.

Alonso, A., P. Sánchez, and J. L. Martínez. 2001. Environmental selection of antibiotic resistance genes. Environ. Microbiol. 3:1-9.

Anonymous. 2014. UK Standards for Microbiology InvestigationsIdentification of Staphylococcus species, Micrococcus species and Rothia species. Ed. Standards Unit, Microbiology Services, PHE, Bacteriology - Identification, ID 7, Issue no: 3, Issue date: 12.11.14, Page 1 of 32 .

Baba, T., K. Kuwahara-Arai, I. Uchiyama, F. Takeuchi, T. Ito, and K. Hiramatsu. 2009. Complete genome sequence of Macrococcus caseolyticus strain JCSCS5402, [corrected] reflecting the ancestral genome of the human pathogenic staphylococci. J. Bacteriol. 191:1180-1190.

Becker, K., S. van Alen, E. A. Idelevich, N. Schleimer, J. Seggewiß, A. Mellmann, U. Kaspar, and G. Peters. 2018. Plasmid-encoded transferable $m e c \mathrm{~B}-$ mediated methicillin resistance in Staphylococcus aureus. Emerg. Infect. Dis. 24:242-248.

Bockelmann, W., and T. Hoppe-Seyler. 2001. The surface flora of bacterial smear-ripened cheeses from cow's and goat's milk. Int. Dairy J. 11:307-314.

CDC (Centers for Disease control and Prevention). 2015. Oxacillin resistant Staphylococcus aureus on PulseNet (OPN): Laboratory protocol for molecular typing of $S$. aureus by pulsed field gel electrophoresis (PFGE). Accessed Feb. 8, 2019. http://www.cdc.gov/ $\mathrm{mrsa} / \mathrm{pdf} /$ ar_mras_PFGE_s_aureus.pdf.

Chajęcka-Wierzchowska, W., A. Zadernowska, B. Nalepa, M. Sierpinska, and L. Laniewska-Trokenheim. 2015. Coagulase-negative staphylococci (CoNS) isolated from ready-to-eat food of animal origin-Phenotypic and genotypic antibiotic resistance. Food Microbiol. 46:222-226.

CLSI (Clinical and Laboratory Standards Institute). 2008. Performance Standards for Antimicrobial Disk and Dilution Susceptibility Tests for Bacteria Isolated from Animals; Approved Standard. 3rd ed. CLSI document M31-A3. CLSI, Wayne, PA.
Coton, E., M.-H. Desmonts, S. Leroy, M. Coton, E. Jamet, S. Christieans, P.-Y. Donnio, I. Lebert, and R. Talon. 2010. Biodiversity of coagulase-negative staphylococci in French cheeses, dry fermented sausages, processing environments and clinical samples. Int. J. Food Microbiol. 137:221-229.

D'Andrea, M. M., E. Nuelco, F. Luzzaro, T. Giani, R. Migliavacca, F. Vailati, V. Kroumova, L. Pagani, and G. M. Rossolini. 2006. CMY16, a novel acquired AmpC-type beta-lactamase of the CMY/LAT lineage in multifocal monophyletic isolates of Proteus mirabilis from northern Italy. Antimicrob. Agents Chemother. 50:618-624.

Delbès, C., and M.-C. Montel. 2005. Design and application of a Staphylococcus-specific single strand conformation polymorphismPCR analysis to monitor Staphylococcus populations diversity and dynamics during production of raw milk cheese. Lett. Appl. Microbiol. 41:169-174.

EUCAST (European Committee on Antimicrobial Susceptibility Testing). 2019. The European Committee on Antimicrobial Susceptibility Testing. Breakpoint tables for interpretation of MICs and zone diameters. Version 9.0, 2019. http://www.eucast.org.

Fontes, C. O., V. L. Silva, M. R. Brandão de Paiva, R. A. Garcia, J. R. Resende, A. B. Ferreira-Machado, and C. G. Diniz. 2013. Prevalence, antimicrobial resistance, and virulence characteristics of mecA-encoding coagulase-negative staphylococci isolated from soft cheese in Brazil. J. Food Sci. 78:M594-M599.

Gevers, D., M. Danielsen, G. Huys, and J. Swings. 2003. Molecular characterization of tet(M) genes in Lactobacillus isolates from different types of fermented dry sausage. Appl. Environ. Microbiol. 69:1270-1275.

Guerra, B., S. M. Soto, J. M. Argüelles, and M. C. Mendoza. 2001. Multidrug resistance is mediated by large plasmids carrying a class 1 integron in the emergent Salmonella enterica serotype [4,5,12:i:-]. Antimicrob. Agents Chemother. 45:1305-1308.

Hájek, V., H. Meugnier, M. Bes, Y. Brun, F. Fiedler, Z. Chmela, Y. Lasne, J. Fleurette, and J. Freney. 1996. Staphylococcus saprophyticus ssp. bovis sp. nov., isolated from bovine nostrils. Int. J. Syst. Bacteriol. 46:792-796.

Hasman, H., D. Mevius, K. Veldman, I. Olesen, and F. M. Aarestrup. 2005. beta-Lactamases among extended-spectrum beta-lactamase (ESBL)-resistant Salmonella from poultry, poultry products and human patients in The Netherlands. J. Antimicrob. Chemother. $56: 115-121$.

Hedman, P., O. Ringertz, B. Eriksson, P. Kvarnfors, M. Andersson, L. Bengtsson, and K. Olsson. 1990. Staphylococcus saprophyticus found to be a common contaminant of food. J. Infect. 21:11-19.

Hendriksen, R. S., M. Mikoleit, C. Kornschober, R. L. Rickert, S. V. Duyne, C. Kjelso, H. Hasman, M. Cormican, D. Mevius, J. Threlfall, F. J. Angulo, and F. M. Aarestrup. 2009. Emergence of multidrug-resistant Salmonella Concord infections in Europe and the United States in children adopted from Ethiopia, 2003-2007. Pediatr. Infect. Dis. J. 28:814-818.

Hovelius, B., and P.-A. Mardh. 1984. Staphylococcus saprophyticus as a common cause of urinary tract infections. Rev. Infect. Dis. 6:328-337.

Hummel, A., W. H. Holzapfel, and C. M. A. P. Franz. 2007. Characterisation and transfer of antibiotic resistance genes from enterococci isolated from food. Syst. Appl. Microbiol. 30:1-7. 
Irlinger, F. 2008. Safety assessment of dairy microorganisms: Coagulase-negative staphylococci. Int. J. Food Microbiol. 126:302-310.

Irlinger, F., S. Layec, S. Sandra Hélinck, and E. Eric Dugat-Bony. 2015. Cheese rind microbial communities: Diversity, composition and origin. FEMS Microbiol. Lett. 362:1-11.

Irlinger, F., A. Morvan, N. El Solh, and J. L. Bergerem. 1997. Taxonomic characterization of coagulase-negative staphylococci in ripening flora from traditional French cheeses. Syst. Appl. Microbiol. 20:319-328.

IWG-SCC (International Working Group on the Classification of Staphylococcal Cassette Chromosome Elements). 2009. Classification of staphylococcal cassette chromosome mec (SCCmec): Guidelines for reporting novel SCCmec elements. Antimicrob. Agents Chemother. 53:4961-4967.

Jorgensen, J. H., and M. J. Ferraro. 2009. Antimicrobial susceptibility testing: A review of general principles and contemporary practices. Clin. Infect. Dis. 49:1749-1755.

Kaase, M., S. Lenga, S. Friedrich, F. Szabados, T. Sakinc, B. Kleine, and S. G. Gatermann. 2008. Comparison of phenotypic methods for penicillinase detection in Staphylococcus aureus. Clin. Microbiol. Infect. 14:614-616.

Kehrenberg, C., and S. Schwart. 2006. Distribution of florfenicol resistance genes fexA and cfr among chloramphenicol-resistant Staphylococcus isolates. Antimicrob. Agents Chemother. 50:1156-1163.

Kürekci, C. 2016. Short communication: Prevalence, antimicrobial resistance, and resistance traits of coagulase-negative staphylococci isolated from cheese samples in Turkey. J. Dairy Sci. 99:2675-2679.

Liu, D., T. Chai, X. Xia, Y. Gao, Y. Cai, X. Li, Z. Miao, L. Sun, H. Hao, U. Roesler, and J. Wang. 2012. Formation and transmission of Staphylococcus aureus (including MRSA) aerosols carrying antibiotic-resistant genes in a poultry farming environment. Sci. Total Environ. 426:139-145.

MacFadyen, A. C., E. A. Fisher, B. Costa, C. Cullen, and G. K. Paterson. 2018. Genome analysis of methicillin resistance in Macrococcus caseolyticus from dairy cattle in England and Wales. Microb. Genom. 4:e000191.

McMahon, M. A. S., J. Xu, J. E. Moore, I. S. Blair, and D. A. McDowell. 2007. Environmental stress and antibiotic resistance in foodrelated pathogens. Appl. Environ. Microbiol. 73:211-217.

Mellmann, A., K. Becker, C. von Eiff, U. Keckevoet, P. Schumann, and D. Harmsen. 2006. Sequencing and staphylococci identification. Emerg. Infect. Dis. 12:333-336.

Montel, M. C., S. Buchin, A. Mallet, C. Delbes-Paus, D. A. Vuitton, N. Desmasures, and F. Berthier. 2014. Traditional cheeses: rich and diverse microbiota with associated benefits. Int. J. Food Microbiol. 177:136-154.

Mounier, J., S. Goerges, R. Gelsomino, M. Vancanneyt, K. Vandemeulebroecke, B. Hoste, N. M. Brennan, S. Scherer, J. Swings, G. F. Fitzgerald, and T. M. Cogan. 2006. Sources of the adventitious microflora of a smear-ripened cheese. J. Appl. Microbiol. 101:668-681.

Mounier, J., M. C. Rea, P. M. O'Connor, G. F. Fitzgerald, and T. M. Cogan. 2007. Growth characteristics of Brevibacterium, Corynebacterium, Microbacterium,and Staphylococcus spp. isolated from surface-ripened cheese. Appl. Environ. Microbiol. 73:7732-7739.

Neve, H., J. Dietrich, and K. J. Heller. 2005. A short note on longterm stability of Lactococcus lactis bacteriophages in cheese brine. Kieler Milchwirtsch. Forschungs. 57:191-200.

Nunes, R. S. C., C. P. de Souza, K. S. Pereira, E. Mere Del Aguila, and V. M. F. Pascholain. 2016. Identification and molecular phylogeny of coagulase-negative staphylococci isolates from Minas Frescal cheese in southeastern Brazil: Superantigenic toxin production and antibiotic resistance. J. Dairy Sci. 99:2641-2653.

Olesen, I., H. Hasman, and F. M. Aarestrup. 2004. Prevalence of betalactamases among ampicillin-resistant Escherichia coli and Salmonella isolated from food animals in Denmark. Microb. Drug Resist. 10:334-340.
Oliveira, A. M., N. T. N. Miya, A. S. Sant'Ana, and J. L. Pereira. 2010. Behaviour and enterotoxin production by coagulase negative Staphylococcus in cooked ham, reconstituted skimmed milk, and confectionary cream. J. Food Sci. 75:M475-M481.

Organji, S. R., H. H. Abulreesh, K. Elbanna, G. E. H. Osman, and M. H. K. Almalki. 2018. Diversity and characterizationof Staphylococcus spp. in food and dairy Products: a foodstuff safety assessment. J. Microbiol. Biotechnol. Food Sci. 7:586-593.

Poyart, C., G. Quesne, C. Boumaila, and P. Trieu-Cuot. 2001. Rapid and accurate species-level identification of coagulase-negative staphylococci by using the sodA gene as a target. J. Clin. Microbiol. 39:4296-4301.

Rall, V. L. M., F. P. Vieira, R. Rall, R. L. Vieitis, A. Fernandes Jr., J. M. G. Candeias, K. F. G. Cardoso, and J. P. Araújo Jr.. 2008. PCR detection of staphylococcal enterotoxin genes in Staphylococcus aureus strains isolated from raw and pasteurized milk. Vet. Microbiol. 132:408-413.

Raz, R., R. Colodner, and C. M. Kunin. 2005. Who are you-Staphylococcus saprophyticus? Clin. Infect. Dis. 40:896-898.

Resch, M., V. Nagel, and C. Hertel. 2008. Antibiotic resistance of coagulase-negative staphylococci associated with food and used in starter cultures. Int. J. Food Microbiol. 127:99-104.

Rodrigues, M. X., N. C. C. Silva, J. Hellmeister Trevilin, M. M. B. Cruzado, T. S. Miu, F. R. Sanches Duarte, C. J. Contreras Castillo, S. G. Canniatti-Brazaca, and E. Porto. 2017. Molecular characterization and antibiotic resistance of Staphylococcus spp. isolated from cheese processing plants. J. Dairy Sci. 100:5167-5175.

Sanger, F., and A. R. Coulson. 1975. A rapid method for determining sequences in DNA by primed synthesis with DNA polymerase. J. Mol. Biol. 94:441-448.

Schwendener, S., K. Cotting, and V. Perreten. 2017. Novel methicillin resistance gene mecD in clinical Macrococcus caseolyticus strains from bovine and canine sources. Sci. Rep. 7:43797. https://doi .org/10.1038/srep43797.

Stegger, M., P. S. Andersen, A. Kearns, B. Pichon, M. A. Holmes, G. Edwards, F. Laurent, C. Teale, R. Skov, and A. R. Larsen. 2012 Rapid detection, differentiation and typing of methicillin-resistant Staphylococcus aureus harbouring either mecA or the new mecA homologue mecA(LGA251). Clin. Microbiol. Infect. 18:395-400.

Stinear, T. P., D. C. Olden, P. D. R. Johnson, J. K. Davies, and M. L. Grayson. 2001. Enterococcal vanB resistance locus in anaerobic bacteria in human faeces. Lancet 357:855-856.

Sutherland, B. J. 2002. Salting of cheese. Pages 293-300 in Encyclopedia of Dairy Sciences. Vol. 1. K. Roginski, J. W. Fuquay, and P. F. Fox, ed. Academic Press, Amsterdam, the Netherlands.

Vernozy-Rozand, C., C. Mazuy, G. Perrin, F. Haond, M. Bes, Y. Brun, and J. Fleurette. 1996a. Identification of Micrococcaceae isolated from goat's milk and cheese in the Poitou-Charentes region. Int. J. Food Microbiol. 30:373-378.

Vernozy-Rozand, C., C. Mazuy, G. Prevost, C. Lapeyre, M. Bes, Y. Brun, and J. Fleurette. 1996b. Enterotoxin production by coagulase-negative staphylococci isolated from goats' milk and cheese. Int. J. Food Microbiol. 30:271-280.

Vliegenthart, J. S., P. A. Ketelaar-Van Gaalen, and J. A. Van De Klundert. 1989. Nucleotide sequence of the aacC2 gene, a gentamicin resistance determinant involved in a hospital epidemic of multiply resistant members of the family Enterobacteriaceae. Antimicrob. Agents Chemother. 33:1153-1159.

von Rheinbaben, K. E., and R. M. Hadlok. 1981. Rapid distinctionbetween micrococci and staphylococci with furazolidone agars. Antonie van Leeuwenhoek 47:41-51.

Yan, J. J., W. C. Ko, Y. C. Jund, C. L. Chuang, and J. J. Wu. 2002. Emergence of Klebsiella pneumoniae isolates producing inducible DHA-1 beta-lactamase in a university hospital in Taiwan. J. Clin. Microbiol. 40:3121-3126.

Zhang, Z., S. Schwartz, L. Wagner, and W. Miller. 2000. A greedy algorithm for aligning DNA sequences. J. Comput. Biol. 7:203-214. 